\title{
Impacts of climate and land use changes on river discharge in a small watershed: a case study of the Lam Chi subwatershed, northeast Thailand

\author{
Patchares Chacuttrikul, Masashi Kiguchi and Taikan Oki \\ Institute of Industrial Science, The University of Tokyo, Japan
}

\begin{abstract}
:
The impacts of climate and land use changes on river discharge in the Lam Chi subwatershed in northeast Thailand were assessed using the H08 model. We calibrated and validated the model based on land use type using observational data from the Royal Irrigation Department and evaluated it using the Nash-Sutcliffe Efficiency Coefficient. After calibration, we used climate data from CMIP5 for 2022-2031 and land use data projected by the CLUE model to estimate future river discharge. We found that discharge will increase due to increases in precipitation between the past (1986-1995) and future (2022-2031). Discharge in the forested area is lower than that in the agricultural area due to differences in soil depth, the subsurface flow rate, and evapotranspiration. The main factor affecting discharge is plant evapotranspiration. Furthermore, the impact of land use change is smaller than that of climate change in determining the progression from current to future discharge, whereas the opposite was observed for the transition from the historical to more recent past.
\end{abstract}

KEYWORDS climate change; land use change; river discharge; Lam Chi subwatershed

\section{INTRODUCTION}

At present, flooding and water shortages are global problems (Wetherald and Manabe, 2002) that are influenced by natural factors and human activities, such as climate and land use change (IPCC, 2007). Climate change has other effects, such as changes in the amount of ice on the ocean and land (Neill et al., 2017), temperature, and hydrology (IPCC, 2013). Climate change has resulted in increased runoff in southern and eastern Asia during the wet season, and water may not be available during the dry season (Arnell, 2004). In addition to problems related to climate change, land use change causes other problems. Land use change has significant impacts on natural resources, including water, soil, and plants (Lawler et al., 2013). The ongoing expansion of agricultural areas in Asia has sharply reduced the area of forest. Deforestation affects the hydrological cycle and increases soil erosion, flooding, and landslides (Wu, 2008). These land use activities have had substantial negative consequences, including increased anthropogenic $\mathrm{CO}_{2}$ emissions, deteriorated air and water quality, and altered regional climates (Zhao et al., 2006). However, whether climate change or land use change has the greater effect on river discharge is not clear.

Thailand is facing many problems related to water, with floods and droughts as the two most prominent (Komori et al., 2012). Many studies have examined the relationship between river discharge and climate change in Thailand. Watanabe et al. (2014) projected future discharge of the Chao Phraya River using general circulation models (GCMs) and the H08 model. Their results suggested that future river discharge may increase by $60-90 \%$ when compared with river discharge in the reference period (1980 1999) and peak in September. Champathong et al. (2013) investigated discharge in the Chao Phraya River basin and evaluated the uncertainty in future climate projections using the Meteorological Research Institute Atmospheric General Circulation Model (MRI-AGCM). Most research has shown that precipitation is likely to increase in the future, and that this change may increase river discharge, which will peak in the middle of the wet period in Thailand.

In comparison, few studies have examined the impact of land use change on river discharge in Thailand. Petchprayoon et al. (2010) studied the hydrological impact of land use/land cover change in the Yom River watershed, in northern Thailand. They showed that the expansion of urban areas by $132 \%$ (from $210 \mathrm{~km}^{2}$ in 1990 to $488 \mathrm{~km}^{2}$ in 2006) resulted in a positive temporal trend in river discharge. Population growth has led to increased demand for agricultural land, which has resulted in the destruction of forest areas and land use change. These changes will affect the water cycle and likely river discharge, although this issue has not been clarified.

Land use in the Lam Chi subwatershed of the Mun watershed in northeast Thailand has changed dramatically from more than $90 \%$ forest to agricultural areas. The remaining forest occupies less than $10 \%$ of the total area, while agricultural areas cover more than $65 \%$ of the total area. Therefore, we estimated the change in discharge with climate and land use change to understand the future impacts of climate and land use changes on river discharge in such a small watershed.

Correspondence to: Patchares Chacuttrikul, Institute of Industrial Science, The University of Tokyo, 4-6-1 Komaba Meguro-ku, Tokyo 153-8505, Japan. E-mail: puy275@gmail.com 


\section{DATA AND METHODS}

To calculate river discharge, we used the land surface process and river module of the H08 model, which is a global hydrological model (Hanasaki and Yamamoto, 2010) that integrates six modules (Hanasaki et al., 2008).

\section{Data}

Climate data

We used the downscale daily climate data in 5-arc minute resolution from four datasets: 1) the Water and Global Change (WATCH) forcing data (WFD; Weedon et al., 2011) for 1963-1972, 2) the Second Global Soil Wetness Project (GSWP2; Dirmeyer et al., 2006) for 1986$1995,3)$ the WATCH Forcing Data methodology applied to
ERA-Interim data (WFDEI; Weedon et al., 2014) for 20052014, and 4) three climate models (MIROC5, IPSL, and MRI-CGCM3) included in phase 5 of the Coupled Model Intercomparison Project (CMIP5; Taylor et al., 2012) for 2022-2031. River discharge data from seven observation stations (Figure 1) in the Lam Chi subwatershed belonging to the Royal Irrigation Department were used to calibrate and validate the models.

Land use data

The Lam Chi subwatershed has a total area of $4,954 \mathrm{~km}^{2}$. In 1963, most of the study area was covered by forest; according to land use data from the Royal Forest Department, the forest covered about $4,862 \mathrm{~km}^{2}$ or $98 \%$ of the total area (Figure 1a). Land use data for the Lam Chi subwatershed from 1990 (Figure 1b) and 2009 (Figure 1c) provided by the Land Development Department indicate that
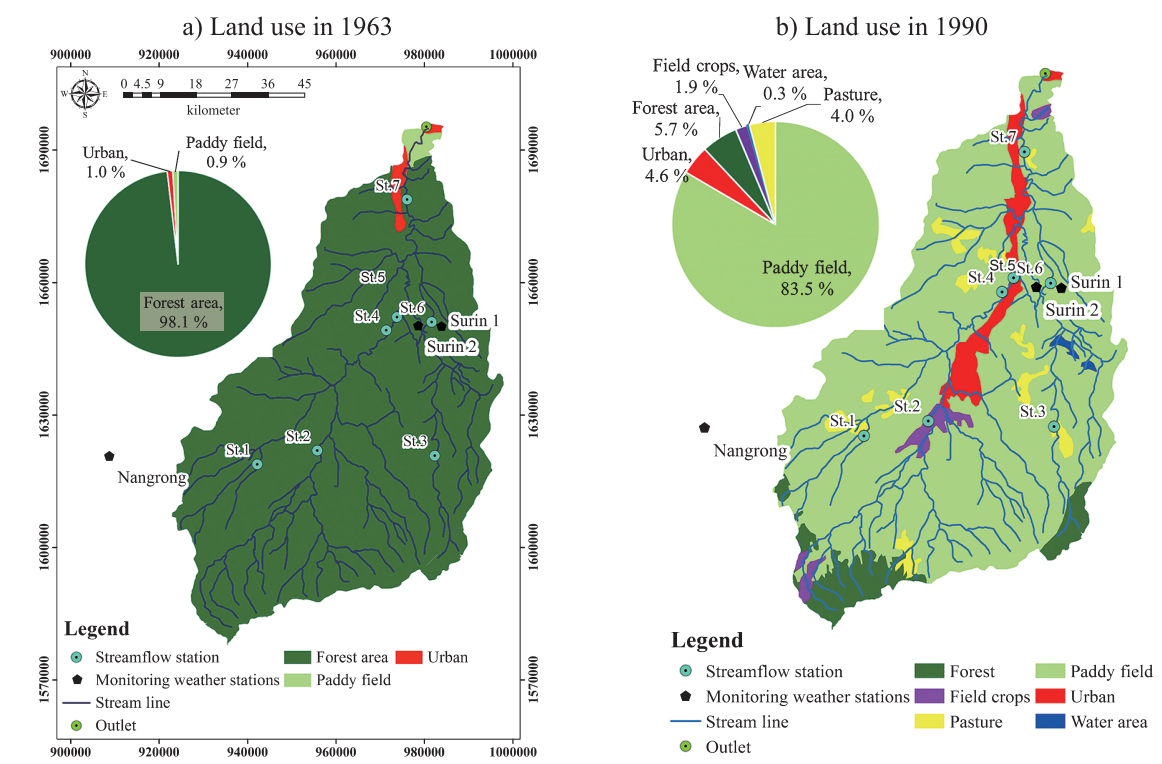

c) Land use in 2009
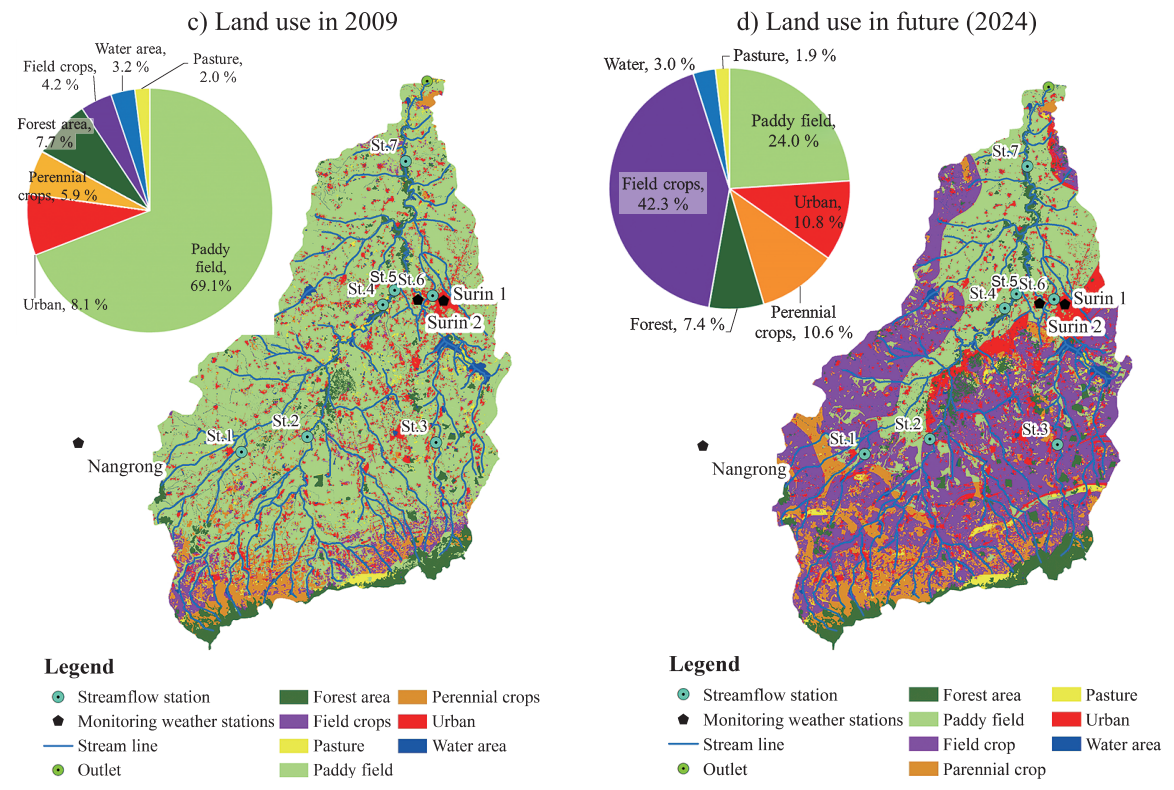

Figure 1. Land use in the Lam Chi subwatershed in a) 1963, b) 1990, c) 2009, and d) the future (2024). The streamflow stations are (1) Ban Khokkachao, (2) Ban Charokyai, (3) Ban Buchek, (4) Ban Lalun, (5) Ban Lamchi, (6) Surin, and (7) Ban Lumdin 
the area of forest declined continuously after 1963 due to forest concessions and the demand for paddy fields. In 1990 , paddy fields covered $4,135 \mathrm{~km}^{2}$ or $83 \%$ of the total area; in 2009 , paddy fields covered only $3,422 \mathrm{~km}^{2}$ or $69 \%$ of the total area. Furthermore, we projected the future land use (Figure 1d) using the CLUE model (Conversion of Land Use and its Effects modelling framework), which was developed to simulate land use change using empirically quantified relationships between land use and its driving factors (Verburg, 2010). In this study, we used the land use in 2009 as baseline data and topography data (slope, elevation and urban area) as a driving factor for the simulation of future land use. In this simulation, the paddy fields were converted into other types of land use.

\section{Methodology}

\section{Data preparation}

The flow direction data at 5-arc minute resolution for the Lam Chi subwatershed used for the H08 models were prepared from elevation data from a topographic map produced by the Royal Thai Survey Department using the Geographical Information System (GIS).

We examined 11 cases (Table I) to compare the impacts of land use and climate changes. The following climate and land use data were considered: historical data (hereafter, $\mathrm{H}$; climate in 1963-1972 and land use in 1963), past data (hereafter, P; climate in 1986-1995 and land use in 1990), current data (hereafter, C; climate in 2005-2014 and land use in 2009), and future data (hereafter F; climate in 20222031 and land use in the future (2024)). To estimate the impact of climate change on river discharge, we compared the results using climate data for different periods and land use data for the same period; to estimate the impact of land use change on river discharge, we compared the results using climate data for the same period and land use data for different periods. For example, the results obtained using climate data for 1986-1995 (case P-P) were compared with those obtained using climate data for 2005-2014 (case C-P) and 2022-2031 (case F-P) based on land use in 1990. By contrast, the results obtained using the land use data for 1990 (case P-P) were compared with those obtained using land use data for 1963 (case P-H) based on climate data for 1986-1995.

\section{Calibration of $\mathrm{H} 08$ model}

Parameters of the H08 model that are susceptible to river discharge and related to land use (Mateo et al., 2012) are soil depth (SD), bulk transfer coefficient (CD), time constant for daily maximum subsurface runoff $(\tau)$, and a shape parameter $(\gamma)$ that is related to subsurface flow (Hanasaki et al., 2014). The model can be calibrated by changing the values of the parameters based on land use type and evaluated using the Nash-Sutcliffe Efficiency Coefficient (NSE). When the NSE value is close to 1 , both outcomes agree well; when the NSE value is close to 0, the groups are poorly related (Suwanlertcharoen, 2011). First, we calibrated the river discharge simulated by the model using climate data for 2005-2014 and land use data for 2009 (case C-C) with observational data from four stations. Then, we used the value from the calibration to validate the model outputs for 1963-1972 (case H) and 1986-1995 (case P). The details of the optimum parameter values and the accuracy of the model are shown in Tables SI and SII, respectively.

\section{RESULTS AND DISCUSSION}

\section{River discharge of Lam Chi subwatershed}

We estimated discharge from the Lam Chi subwatershed in case $\mathrm{C}-\mathrm{C}$ for calibration and in cases $\mathrm{H}-\mathrm{H}$ and P-P for validation of the H08 model. Evaluation of the accuracy and compatibility of the monthly flow rate using measurements of the Lam Chi subwatershed and the H08 model yielded NSE values for case C-C at stations 4-7 of 0.60 (Figure 2a), 0.48 (Figure 2b), 0.80 (Figure 2c), and 0.64, respectively (Figure $2 \mathrm{~d}$ ). The NSE values indicate that the model is well calibrated and can be used for simulation in cases of land use change. However, the NSE values show the validity of evaluation over 10 years and there were errors in some month, such as in August to November in 2008 of station 5 . This error may be due to the coarse spatial resolution.

\section{Impacts of climate changes on the river discharge}

Considering the impact of climate change from the historical to recent past, the monthly rainfall in case $\mathrm{H}-\mathrm{H}$ is likely higher than that in case P-H (Figure 3a) and the river discharge in case $\mathrm{H}-\mathrm{H}$ is greater than that in case $\mathrm{P}-\mathrm{H}$ (Figure 3e). For the past, we found that the monthly rainfall in cases C-P and F-P was higher than that in case P-P (Figure 3d). Consequently, discharge in cases C-P and F-P was greater than that in case P-P. In addition, the river discharge simulated for land use in 2009 (C) and in the future (F) showed a tendency in the same direction. These results imply that the monthly rainfall and river discharge for the climate in 2005-2014 (C) are less than the results for the

Table I. Details of the 11 scenarios. H means historical, i.e. the climate in 1963-1972 and land use in 1963; P means past, i.e. the climate in 1986-1995 and land use in 1990; C means current, i.e. the climate in 2005-2014 and land use in 2009; and F means future, i.e. the climate in 2022-2031 and land use in the future

\begin{tabular}{|c|c|c|c|c|c|c|c|c|c|c|c|}
\hline \multirow{2}{*}{ Case } & \multicolumn{2}{|c|}{ Data (Year) } & \multirow{2}{*}{$\begin{array}{c}\text { NSE from } \\
\text { station } 5\end{array}$} & \multirow{2}{*}{ Case } & \multicolumn{2}{|c|}{ Data (Year) } & \multirow{2}{*}{$\begin{array}{c}\text { NSE from } \\
\text { station } 5\end{array}$} & \multirow{2}{*}{ Case } & \multicolumn{2}{|c|}{ Data (Year) } & \multirow{2}{*}{$\begin{array}{c}\text { NSE from } \\
\text { station } 5\end{array}$} \\
\hline & Climate & Land use & & & Climate & Land use & & & Climate & Land use & \\
\hline $\mathrm{H}-\mathrm{H}$ & 1963-1972 & 1963 & 0.41 & P-H & 1986-1995 & 1963 & 0.47 & $\mathrm{C}-\mathrm{F}$ & 2005-2014 & Future & - \\
\hline H-P & 1963-1972 & 1990 & 0.20 & P-P & 1986-1995 & 1990 & 0.61 & F-P & $2022-2031$ & 1990 & - \\
\hline \multirow[t]{2}{*}{$\mathrm{H}-\mathrm{C}$} & 1963-1972 & 2009 & 0.15 & C-P & 2005-2014 & 1990 & 0.48 & $\mathrm{~F}-\mathrm{C}$ & $2022-2031$ & 2009 & - \\
\hline & & & & $\mathrm{C}-\mathrm{C}$ & 2005-2014 & 2009 & 0.48 & F-F & $2022-2031$ & Future & - \\
\hline
\end{tabular}




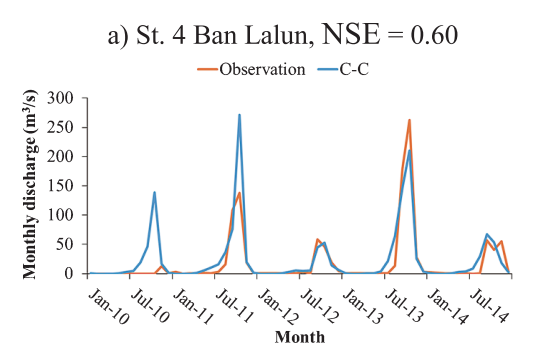

c) St. 6 Surin, NSE $=0.80$

-Observation $-\mathrm{C}-\mathrm{C}$

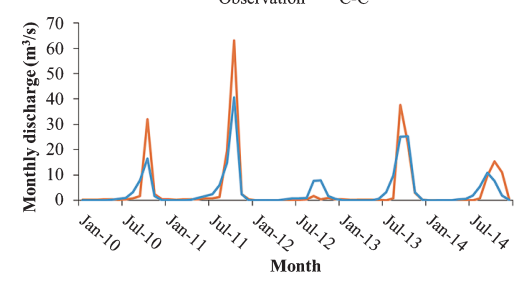

b) St. 5 Ban Lamchi, NSE $=0.48$ -Observation $-\mathrm{C}-\mathrm{C}$

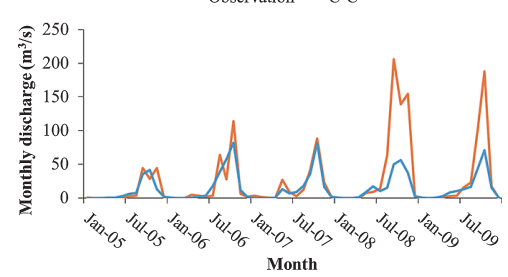

d) St. 7 Ban Lumdin, NSE $=0.64$

-Observation $-\mathrm{C}-\mathrm{C}$

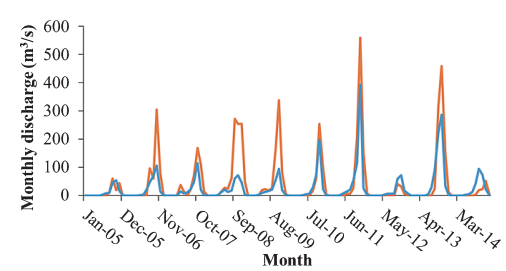

Figure 2. The calibration evaluated using the Nash-Sutcliffe Efficiency Coefficient (NSE). An NSE value close to 1 indicates that the two cases are similar, whereas a value close to 0 indicates that the cases are poorly related

climate in 2022-2031 (F) (Figure 3b and 3f). Consequently, the main climate factor affecting river discharge is taken to be rainfall.

\section{Impacts of land use changes on the river discharge}

After performing the calibration, we adjusted the parameter related to land use type and used different values to estimate the river discharge in the case of climate and land use change.

(1) using historical climate data (1963-1972)

Considering the three cases based on the historical climate, we found that discharge was higher in cases H-P and $\mathrm{H}-\mathrm{C}$ than in case $\mathrm{H}-\mathrm{H}$, and that case H-P was only slightly higher than case H-C in August, September, and October (Figure $4 \mathrm{a}$ and Figure S2). These results were attributed to the fact that most of the land in case H-H is forest, which results in a high evapotranspiration rate.

\section{(2) using climate data in the past (1986-1995)}

Monthly river discharge in case $\mathrm{P}-\mathrm{H}$, when most of the land was forest, was lower than that in case P-P, when most of the land was paddy fields (Figure 4b), likely due to the high evapotranspiration rate in the forested areas (Table SIII). In forests, $89-97 \%$ of the total rainfall evapotranspired during 1986-1995; by comparison, in paddy fields evapotranspiration accounts for $83-93 \%$ of the total rainfall.

(3) using climate data in the current (2005-2014)

Because most land use in cases C-C and C-P is paddy fields, the discharge in both cases is very similar. The discharge in case C-F, in which most of the area is field crops, is lower than that in cases C-P and C-C (Figure 4c) only in August, September, and October. This reflects the higher evapotranspiration rate and greater soil depth in crop fields than in paddy fields; rainfall in crop fields is likely to seep into the soil and may contribute more to groundwater. The differences in evapotranspiration, soil depth, and the time constant for the daily maximum subsurface runoff of each land use type result in differences in discharge for each case.

The impact of land use change on discharge is lesser for the land use in case $\mathrm{H}$ (1963, mainly forest) than in cases $\mathrm{P}$ (1990, mainly paddy fields) and C (2009, mainly paddy fields). Moreover, the discharge for cases with $\mathrm{P}$ and $\mathrm{C}$ land use did not differ. The differences in discharge in each case arise from the differences in three factors for each land use type: evapotranspiration, soil depth, and subsurface flow rate. From the water balance of each case (Tables SIII and SIV), which showed that most water in the system will evaporate, we speculate that evapotranspiration is the most influential factor in this area. The leaf area index (LAI) is a primary factor controlling differences in evapotranspiration among plants (Zha et al., 2010). In areas where the LAI is high, such as forests, canopy interception reduces the net precipitation to the soil surface (Simic et al., 2014). When precipitation is intercepted by leaves, more is likely to evaporate into the atmosphere. These factors are part of the water cycle and affect the differences in water balance found in each case.

The H08 model with the calibrated parameters for period C (2005-2014) is capable of capturing the land use changes because simulations with changing land use, such as $\mathrm{P}-\mathrm{H}$, $\mathrm{H}-\mathrm{P}$, and $\mathrm{H}-\mathrm{C}$, produced worse simulations than those with the correct land use, i.e. P-P and H-H (Table SII shows the accuracy of the model).

(4) using climate data in the future (2022-2031)

This study used climate data for the future (2022-2031) and P (1990), C (2009), and F (future) land use to calculate river discharge. We found that the discharge in cases F-P and F-C was greater than that in case F-F in the rainy season. The results for the other months did not differ (Figure 4d) because the evapotranspiration, soil depth, and subsurface flow rate in case F-F are higher than those in cases F-P and F-C. We found no difference between cases F-C and F$\mathrm{P}$ (Figure 4e).

The results considering climate and land use changes showed a clearer effect on the river discharge only in the case of land use change from H (1963) to P (1990; forest to paddy field), whereas only a slight effect was revealed for the case of change from C (2009) to F (paddy field to field crops). In comparison, the small change in rainfall from $\mathrm{C}$ 
a) Monthly rainfall case $\mathrm{P}-\mathrm{H}$ and $\mathrm{H}-\mathrm{H}$

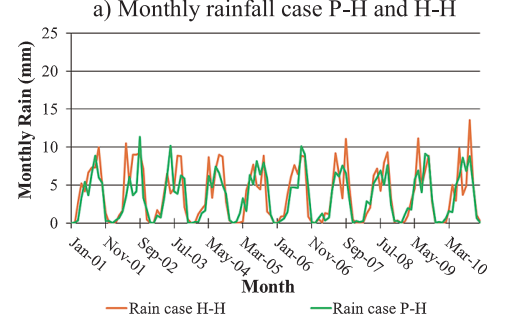

b) Monthly rainfall case F-F and C-F

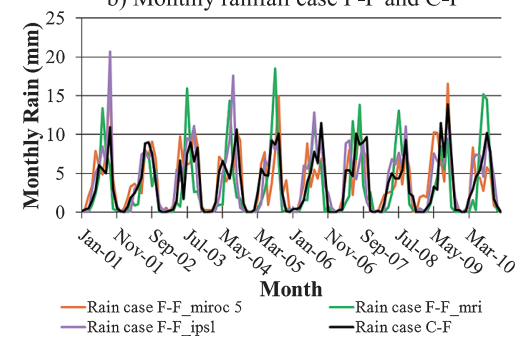

c) Monthly rainfall case C-C and F-C

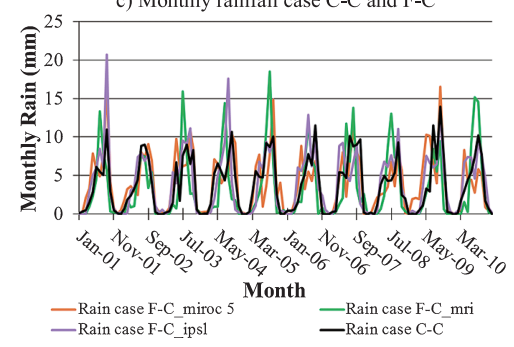

d) Monthly rainfall from case P-P, C-P and F-P

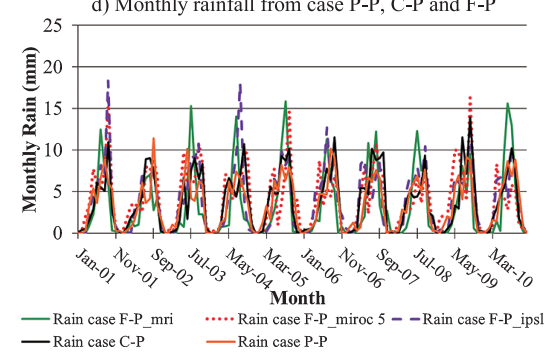

e) Monthly discharge case P-H and H-H

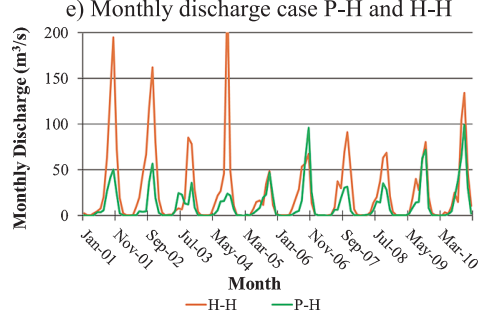

f) Monthly discharge case F-F and C-F

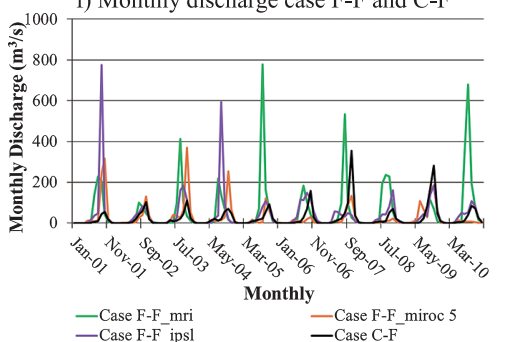

g) Monthly discharge case C-C and F-C

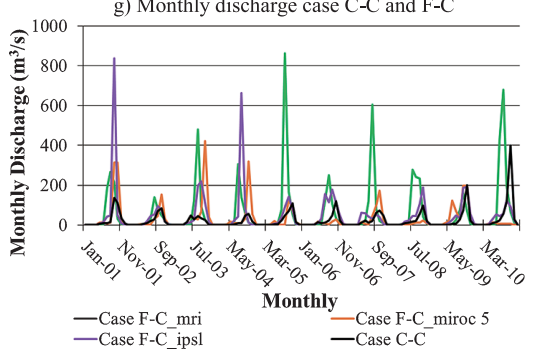

h) Monthly discharge from case P-P, C-P and F-P

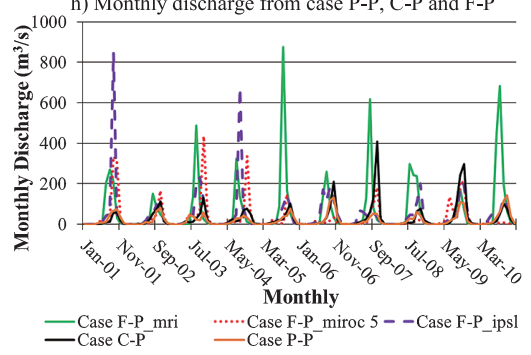

Figure 3. Monthly discharge and rainfall in the case of climate change (P-P, P-H, C-P, F-P and H-H); Year 01 to 10 in the figure refers to year number 1 to 10, for example, 01 means 1986 in case P-P, 2005 in case C-P, 2022 in case F-P and 1963 in case $\mathrm{H}-\mathrm{H}$

(2009) to $\mathrm{F}$ had a tremendous effect on river discharge (Figures S1 and S2). For example, in cases C-F and F-F, the rainfall for period $\mathrm{F}$ is slightly higher than that for period $\mathrm{C}$; however, it has a huge impact on river discharge, resulting in a marked difference in river discharge between periods $\mathrm{F}$ and $\mathrm{C}$. Moreover, the change in land use in the Lam Chi subwatershed from forest in $1963(\mathrm{H})$ to agricultural in 1990 (P) affected river discharge more than the change from one type of agriculture in 2009 (C) to another in the future (F). Tables SIII and SIV show the details of the water balance and Tables SV-SVIII show the percentage change in each situation from the historical period to the future.

\section{CONCLUSIONS}

We estimated the river discharge by combining climate and land use data for different periods to try to determine whether climate change or land use change has a greater effect on river discharge. We calibrated the discharge simulated by the model using climate data for 2005-2014 and land use data for 2009 (case C-C) and used the NSE to check the accuracy of the model. This assessment showed that the results for the cases using land use in 1963 and climate data for 1963-1972 (H-H) and land use in 1990 and climate data for 1986-1995 (P-P) are better than those for cases considering land use change, i.e. H-C, H-P, and P-H.

The impact of climate change shows that discharges determined from historical and future climate data are greater than those determined from current and past climate data. In the Lam Chi subwatershed, most rainfall evaporates; for example, $88-90 \%$ of the total rainfall evaporated during 2005-2014. Nevertheless, we showed that the change in rainfall from the current period to the future will affect river discharge. Climate has a great influence on evaporation, and a slight change in climate will thus have a tremendous effect on river discharge. 
a) Monthly river discharge from case $\mathrm{H}-\mathrm{H}, \mathrm{H}-\mathrm{P}$ and $\mathrm{H}-\mathrm{C}$

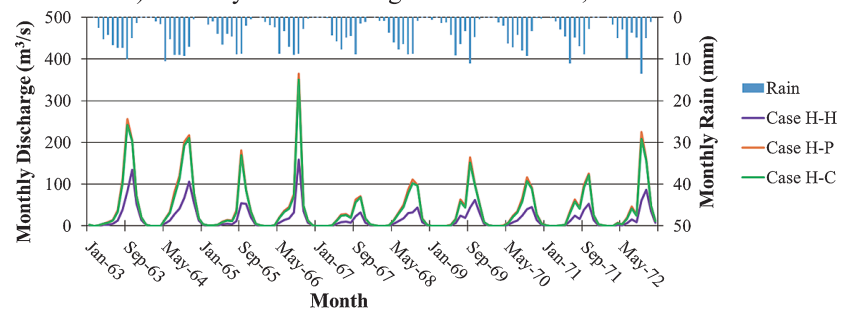

c) Monthly river discharge from case C-P, C-C and C-F

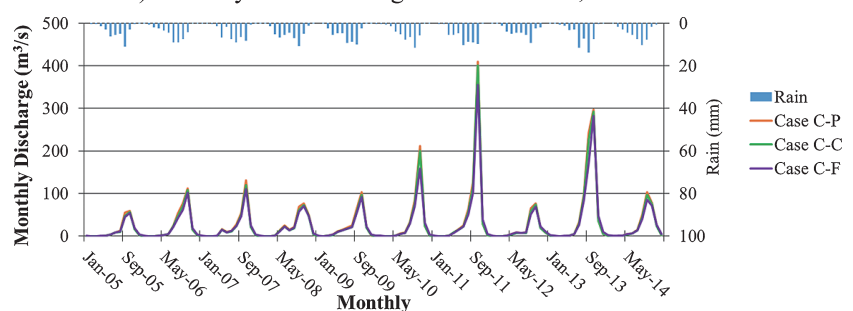

b) Monthly river discharge from case P-P and P-H

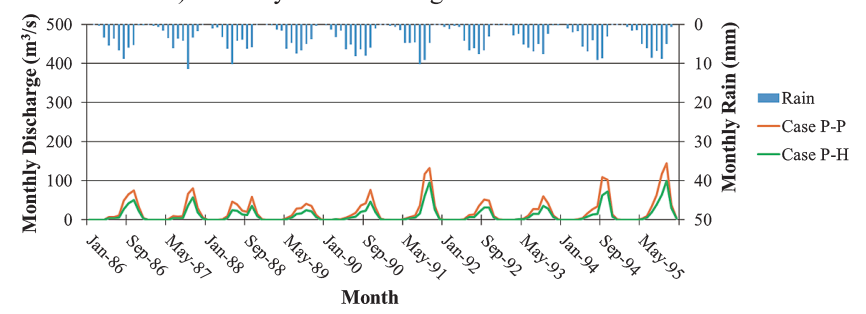

d) Monthly river discharge from case F-C and F-F

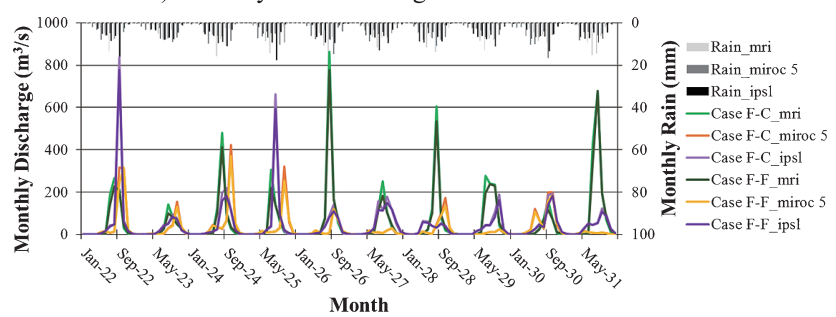

e) Monthly river discharge from case F-P and F-C

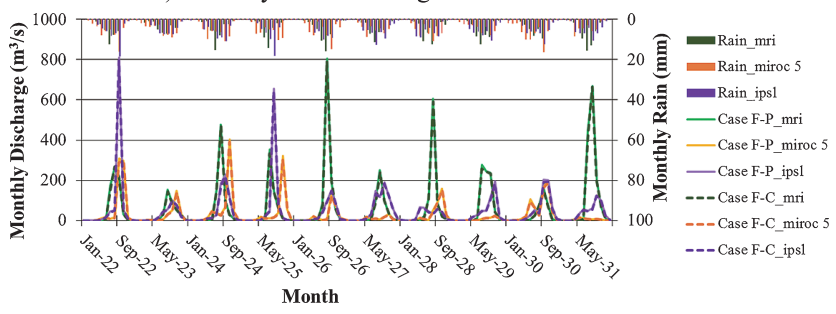

Figure 4. Monthly river discharge in the case of land use change: the monthly river discharge for cases a) $\mathrm{H}-\mathrm{H}, \mathrm{H}-\mathrm{P}$ and $\mathrm{H}-$ C; b) P-P and P-H; c) C-P, C-C, and C-F; d) F-C and F-F; and e) F-P and F-C

In addition, land use in the Lam Chi subwatershed changed considerably from forest to agriculture in the recent past and will likely change from paddy fields to crop fields in the future. The factors that affect river discharge are soil depth, subsurface flow rate, and evapotranspiration from plants. The river discharge from forest is lower than that from paddy fields. The land use change from forest to agricultural area has a greater effect on river discharge than does a change from one type of agriculture to another.

In conclusion, land use change likely had a greater impact than climate change on river discharge during the transition from the historical to recent past. In contrast, during the current period to the future, climate change is likely to have a greater impact than land use change on river discharge. The methodology used to simulate how land use change affects river discharge should be applicable to other studies.

\section{ACKNOWLEDGMENTS}

The study was supported by the Science and Technology Research Partnership for Sustainable Development, JSTJICA, Japan. The authors are grateful to the Thai Meteorological Department and the Royal Irrigation Department, Thailand for providing us with meteorological and hydrological data.

\section{SUPPLEMENTS}

Figure S1. Monthly climate data; Year 01 to 10 in figure that means year number 1 to 10 , for example, 01 mean 1986 in result of case P, mean 2005 in result of case C, mean 2022 in result of case F and mean 1963 in result of case $\mathrm{H}-\mathrm{H}$

Figure S2. Comparison of monthly river discharge of a) historical and past of climate change, b) historical, past and current of land use change, c) current and future of climate change, and d) current and future of land use change. Unit is $\mathrm{m}^{3} / \mathrm{s}$. In c), we used three GCMs results

Table SI. Results of optimum parameter set calibrated in each land use

Table SII. Nash-Sutcliffe Efficiency Coefficient value from calibration and validation of the model by observation data

Table SIII. Annual Water Balance table

Table SIV. Annual Water Balance table in future case

Table SV. Monthly percentage change of river discharge in each situation (Historical to Past)

Table SVI. Monthly percentage change of river discharge in each situation (Current to Future)

Table SVII. Yearly percentage change of each situation (Historical to Past)

Table SVIII. Yearly percentage change of each situation (Current to Future) 


\section{REFERENCES}

Arnell N. 2004. Climate change and global water resources: SRES emissions and socio-economic scenarios. Global Environmental Change 14: 31-52. DOI: 10.1016/j.gloenvcha. 2003.10.006.

Champathong A, Komori D, Kiguchi M, Sukhapunnaphan T, Oki T, Nakaegawa T. 2013. Future projection of mean river discharge climatology for the Chao Phraya River basin. Hydrological Research Letters 7: 36-41. DOI: 10.3178/hrl.7.36.

Dirmeyer P, Gao X, Zhao M, Guo Z, Oki T, Hanasaki N. 2006. GSWP-2: Multimodel analysis and implications for our perception of the land surface. American Meteorological Society 87: 1381-1398. DOI: 10.1175/BAMS-87-10-1381.

Hanasaki N, Kanae S, Oki T, Masuda K, Motoya K, Shirakawa N, Shen Y, Tanaka K. 2008. An integrated model for the assessment of global water resources-Part 1: Model description and input meteorological forcing. Hydrology and Earth System Sciences 12: 1007-1025. DOI: 10.5194/ hess-12-1007-2008.

Hanasaki N, Yamamoto T. 2010. H08 Manual User's Edition. National Institute for Environmental Studies, Tsukuba, Japan; 76.

Hanasaki N, Saito Y, Chaiyasaen C, Champathong A, Ekkawatpanit C, Saphaokham S, Sukhapunnaphan T, Sumdin S, Thongduang J. 2014. A quasi-real-time hydrological simulation of the Chao Phraya River using meteorological data from the Thai Meteorological Department Automatic Weather Stations. Hydrological Research Letters 8: 9-14. DOI: 10.3178/hrl.8.9.

Intergovernmental Panel on Climate Change (IPCC). 2007. Climate Change: Impacts, Adaptation and Vulnerability. Contribution of Working Group II to the fourth assessment report of the Intergovernmental Panel on Climate Change, Cambridge University Press, Cambridge, UK.

Intergovernmental Panel on Climate Change (IPCC). 2013. Climate Change: The Physical Science Basis. Contribution of Working Group I to the fifth assessment report of the Intergovernmental Panel on Climate Change, Cambridge University Press, Cambridge, UK and NY.

Komori D, Nakamura S, Kiguchi M, Nishijima A, Yamazaki D, Suzuki S, Kawasaki A, Oki K, Oki T. 2012. Characteristics of the 2011 Chao Phraya River flood in Central Thailand. Hydrological Research Letters 6: 41-46. DOI: 10.3178/ HRL.6.41.

Lawler J, Lewis J, Nelson E, Plantinga A, Polasky S, Withey J, Helmers D, Martinuzzi S, Polasky S, Withey J, Helmers D, Martinuzzi S, Pennington D, Radeloff V. 2014. Projected land-use change impacts on ecosystem services in the United States. Proceedings of the National Academy of Sciences of the United States of America (PNAS) 111: 7492-7497. DOI: 10.1073/pnas.1405557111.

Mateo C, Hanasaki N, Komori D, Tanaka K, Yoshimura K, Kiguchi M, Oki T. 2012. Optimization of H08 land surface model parameters in the Chao Phraya River basin to reproduce the 2011 river discharge. Annual Conference of Japan Society of Hydrology and Water Resources, Hiroshima, Japan; 78-79.
Neill B, Oppenheimer M, Warren R, Hallegatte S, Kopp R, Portner H, Scholes R, Birkmann J, Foden W, Licker R, Mach J, Marbaix P, Mastrandrea M, Price J, Takahashi K, Ypersele J, Yohe G. 2017. IPCC reasons for concern regarding climate change risks. Nature Climate Change 7: 28-37. DOI: 10.1038/NCLIMATE3179.

Petchprayoon P, Blanken P, Ekkawatpanit C, Hussein K. 2010. Hydrological impacts of land use/land cover change in a large river basin in central-northern Thailand. International Journal of Climatology 30: 1917-1930. DOI: 10.1002/joc. 2131.

Simic A, Fernandes R, Wang S. 2014. Assessing the Impact of Leaf Area Index on Evapotranspiration and Groundwater Recharge across a Shallow Water Region for Diverse Land Cover and Soil Properties. Journal of Water Resource and Hydraulic Engineering 3: 60-73.

Suwanlertcharoen T. 2011. Application of SWAT Model to Evaluate Runoff and Suspended Sediment from a Small Watershed: A Case Study of Mae Phun Subwatershed, Laplae District, Uttaradit Province. Master's Thesis, Kasetsart University, Bangkok, Thailand; 129.

Taylor E, Stouffer R, Meehl G. 2012. An Overview of CMIP5 and the experiment design. Bulletin of the American Meteorological Society 93: 485-498. DOI: 10.1175/bams-d-11-00094.1.

Verburg P. 2010. CLUE model: The CLUE model framework. Institute for Environmental Studies, VRIJE University Amsterdam, Netherland; 53.

Watanabe S, Hirabayashi Y, Kotsuki S, Hanasaki N, Tanaka K, Mateo C, Kiguchi M, Ikoma E, Kanae S, Oki T. 2014. Application of performance metrics to climate model for projecting future river discharge in the Chao Phraya River basin. Hydrological Research Letters 8: 33-38. DOI: 10.3178/hrl.8.33.

Weedon P, Gomes S, Viterbo P, Shuttleworth J, Blyth E, Österle H, Adam C, Bellouin N, Boucher O, Best M. 2011. Creation of the WATCH Forcing Data and Its Use to Assess Global and Regional Reference Crop Evaporation over Land during the Twentieth Century. Journal of Hydrometeorology 12: 1205-1220. DOI: 10.1175/2011JHM1369.1.

Weedon P, Balsamo G, Bellouin N, Gomes S, Best J, Viterbo P. 2014. The WFDEI meteorological forcing data set: WATCH Forcing Data methodology applied to ERA-Interim reanalysis data. Water Resources Research 50: 7505-7514. DOI: 10.1002/2014WR015638.

Wetherald T, Manabe S. 2002. Simulation of hydrologic changes associated with global warming. Journal of Geophysical Research 107: ACL7-1-ACL7-15. DOI: 10.1029/ 2001JD001195.

Wu J. 2008. Land Use Changes: Economic, Social and Environmental Impacts. A publication of the Agricultural \& Applied Economics Association (AAEA) 23: 6-10.

Zha T, Barr AG, Kamp G, Black TA, McCaughey JH, Flanagan LB. 2010. Interannual variation of evapotranspiration from forest and grassland ecosystems in western Canada in relation to drought. Agricultural and Forest Meteorology 150: 1476-1484. DOI: 10.1016/j.agrformet.2010.08.003.

Zhao S, Peng C, Jiang H, Tian D, Lei X, Zhou X. 2006. Land use change in Asia and the ecological consequences. Ecological Research 21: 890-896. DOI: 10.1007/s11284-006-0048-2. 